\title{
Net precipitation over the Baltic Sea for one year using models and data-based methods
}

\author{
By BARBARA HENNEMUTH ${ }^{1 *}$, ANNA RUTGERSSON ${ }^{2}$, KARL BUMKE ${ }^{3}$, MARCO CLEMENS ${ }^{3}$, \\ ANDERS OMSTEDT ${ }^{4}$, DANIELA JACOB ${ }^{1}$ and ANN-SOFI SMEDMAN ${ }^{5},{ }^{1}$ Max-Planck-Institute for Me- \\ teorology, Hamburg, Germany; ${ }^{2}$ Swedish Meteorological and Hydrological Institute, Norrköping, Sweden; \\ ${ }^{3}$ Institut für Meereskunde, Kiel, Germany; ${ }^{4}$ Department of Earth Sciences, Oceanography, Göteborg Univer- \\ sity, Göteborg, Sweden; ${ }^{5}$ Department of Earth Sciences, Meteorology, Uppsala University, Uppsala, Sweden
}

(Manuscript received 24 April 2002; in final form 3 February 2003)

\begin{abstract}
Precipitation and evaporation over the Baltic Sea are calculated for a one-year period from September 1998 to August 1999 by four different tools, the two atmospheric regional models HIRLAM and REMO, the oceanographic model PROBE-Baltic in combination with the SMHI $(1 \times 1)^{\circ}$ database and Interpolated Fields, based essentially on ship measurements. The investigated period is slightly warmer and wetter than the climatological mean. Correlation coefficients of the differently calculated latent heat fluxes vary between 0.81 (HIRLAM and REMO) and 0.56 (SMHI/PROBE-Baltic and Interpolated Fields), while the correlation coefficients between model fluxes and measured fluxes range from 0.61 and 0.78. Deviations of simulated and interpolated monthly precipitation over the Baltic Sea are less than $\pm 5 \mathrm{~mm}$ in the southern Baltic and up to $20 \mathrm{~mm}$ near the Finnish coast for the one-year period. The methods simulate the annual cycle of precipitation and evaporation of the Baltic Proper in a similar manner with a broad maximum of net precipitation in spring and early summer and a minimum in late summer. The annual averages of net precipitation of the Baltic Proper range from $57 \mathrm{~mm}$ (REMO) to $262 \mathrm{~mm}$ (HIRLAM) and for the Baltic Sea from $96 \mathrm{~mm}$ (SMHI/PROBE-Baltic) to $209 \mathrm{~mm}$ (HIRLAM). This range is considered to give the uncertainty of present-day determination of the net precipitation over the Baltic Sea.
\end{abstract}

\section{Introduction}

Energy and water exchange between the ocean surface and the atmosphere are presently not fully understood or described for today's climate. This has stimulated several international research programmes of which GEWEX (The Global Energy and Water Cycle Experiment) is one. Six continental scale experiments are included within GEWEX in order to increase our understanding of energy and water cycles in different climates. One of these is the Baltic Sea, where the BALTEX project (the Baltic Sea Experiment) (BALTEX, 1995; Raschke et al., 2001) has the scientific

\footnotetext{
* Corresponding author. e-mail: hennemuth@dkrz.de
}

objectives to develop and validate coupled regional models and to investigate the energy and water budget of the Baltic Sea drainage basin. The net precipitation (precipitation minus evaporation) is an important part of the water cycle in the Baltic Sea system. Its derivation includes the difficulty in describing the precipitation in the atmosphere and the evaporation from the sea surface, the latter being very sensitive to both sea surface temperature and ice cover (Omstedt et al., 1997).

In order to investigate the net precipitation over sea the project PEP in BALTEX (Pilot Study of Evaporation and Precipitation in The Baltic Sea) was initiated. PEP was designed as a pilot experiment to the BALTEX main experiment, with the specific objective to study precipitation and evaporation over sea 
(Smedman et al., 1998). Measurements of precipitation and evaporation over sea are used in combination with several models in the project. Thus for the first time precipitation measurements over the Baltic Sea are used for comparison with model simulations. Questions asked in PEP were: How large are the differences in net precipitation for a one-year period obtained by different methods? Are we capable to give reliable results which encourage us to simulate longer periods (10 to $100 \mathrm{yr}$ )? For this purpose, two atmospheric regional models, an oceanographic model, and an interpolation scheme of measured parameters are tested and results are compared. The sensitivity of the different models to differences in for example parameterisation of evaporation is further discussed and some comparisons with measurements are presented for limited periods.

This paper first describes the investigated period in Section 2, briefly introduces the different models with some validations by measurements in Sections 3 and 4 , respectively, including an analysis of the differences in the parameterisation of evaporation. In Section 5 the resulting net precipitation is shown and Section 6 draws conclusions.

\section{The investigated period}

The period September 1998 to August 1999 has been used for the one-year simulation of evaporation and precipitation over the Baltic Sea, as it is embedded in the measuring period of PEP, lasting from May 1998 to October 1999 and it includes the Concentrated Field Effort (CFE), a one-month period from 12 October to 12 November 1998 with intensified measurements at special sites and ship cruises in the Baltic Sea.

The climatological classification of this year is achieved by using data from SYNOP stations around the Baltic Sea, both for temperature and precipitation, and GPCC products (Global Precipitation Climatology Centre at DWD). The precipitation and temperature data are compared to the climatological means of 1961-1990; however, the time period for SST comparisons is the 18-yr period 1981-1998. The synoptic sites are (clockwise, starting in the North): Haparanda (SWE), Vaasa (FIN), Helsinki (FIN), Tallinn (EST), Liepaja (LAT), Hel (POL), Arkona (GER), Kiel (GER), Kopenhaven (DK), Ronne (DK), Visby (SWE), Stockholm (SWE) and Sundsvall (SWE) (Fig. 1).

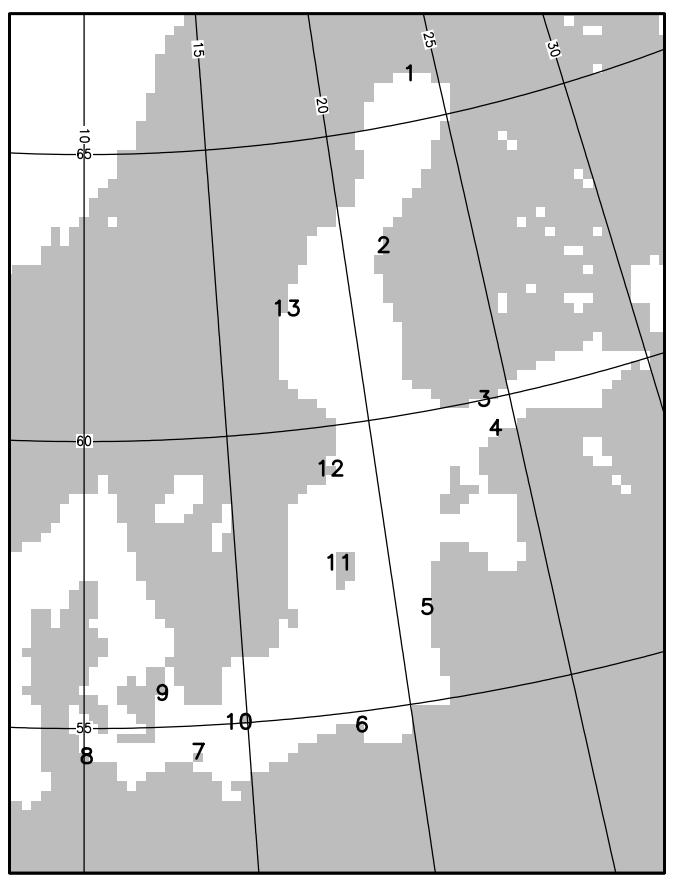

Fig. 1. Baltic Sea with synoptic sites: (1) Haparanda (SWE), (2) Vaasa (FIN), (3) Helsinki (FIN), (4) Tallinn (EST), (5) Liepaja (LAT), (6) Hel (POL), (7) Arkona (GER), (8) Kiel (GER), (9) Kopenhaven (DK), (10) Ronne (DK), (11) Visby (SWE), (12) Stockholm (SWE), (13) Sundsvall (SWE). The PEP measuring sites are Kopparnäs near 3, Christians $\emptyset$ near 10, Östergarnsholm near 11 and Zingst near 7 . The land-sea mask and grid resolution shown is used by the model REMO.

Air temperatures were higher than the climatological mean for all sites. For the southern, western and northern sites the difference from the climatological mean is $0.2-0.5 \mathrm{~K}$ and for the eastern sites even $0.8-$ 0.9 K. The autumn (September-November) of 1998, in particular November, was generally colder than the average: January-August 1999 (except May) were warmer. When using simulated SST from the ocean model PROBE-Baltic (Section 3.3), the investigated year shows a similar deviation compared to the period 1981-1998. During spring and summer 1999, SST was significantly higher than the 18-yr mean in the southern basins, but the difference is only minor in the Bothnian Sea. In autumn 1998 SST was slightly below the long-time mean in the southern basins, but not further north. These temperature deviations from the climatological mean do not a priori cause a larger evaporation, because the autumn months that generally contribute most to the annual evaporation are colder 
and the spring and summer months with small evaporation are warmer.

According to the GPCC data (GPCC, 2001), the selected year was wetter than the climatological mean, especially in the southern part of the Baltic Sea. The same result is given by comparison of the test year with an 18-yr period from 1981 to 1998 using the interpolated synoptic data of the SMHI $(1 \times 1)^{\circ}$ database. The total precipitation of the 13 SYNOP stations at the Baltic Sea coast (Fig. 1) is higher for the 199899 period than the climatological mean. However, less precipitation was observed in the the eastern and central parts of the Baltic Sea coast and more precipitation in all other regions. Maxima occured in October 1998 and in April 1999.

\section{The models}

For the present study the results of three different models are used, the Swedish version of the regional forecast model HIRLAM, the regional climate model REMO and the oceanographic model PROBE-Baltic. In addition, the SMHI $(1 \times 1)^{\circ}$ database for precipitation and two interpolation schemes for precipitation and evaporation (mainly based on ship measurements) are used. The latter two are named here Interpolated Fields.

All models calculate the turbulent surface fluxes of momentum, sensible and latent heat over the sea by bulk formulae using the formalism of the MoninObukhov similarity theory. Thus, the latent heat flux $E$ is described by

$E=\rho \lambda C_{\mathrm{E}} u_{10}\left(q_{10}-q_{\mathrm{s}}\right)$

where $q_{10}$ and $q_{\mathrm{s}}$ are specific humidity at $10 \mathrm{~m}$ height and at the height of the roughness length of water vapour $\left(z_{\mathrm{q}}\right)$, respectively, $u_{10}$ is the horizontal wind speed at $10 \mathrm{~m}$ height, $\rho$ is the air density and $\lambda$ is the specific latent heat of vapourization. The transfer coefficient for water vapour $C_{\mathrm{E}}$ is given by

$C_{\mathrm{E}}=C_{\mathrm{EN}} f_{\mathrm{E}}\left(\frac{z}{L}, z_{0}, z_{\mathrm{q}}\right)$

where $C_{\mathrm{EN}}$ is the neutral transfer coefficient and $f_{\mathrm{E}}$ is a stability function which depends on stability $z / L$ and on the roughness lengths $z_{0}$ for momentum and $z_{\mathrm{q}}$ for water vapour. $z / L$ is the stability parameter, where
$L$ is the Monin-Obukhov stability length, defined as

$L=\frac{u_{*}^{3} T_{\mathrm{v}}}{\kappa g \overline{w^{\prime} T_{\mathrm{v} 0}^{\prime}}}$

where $u_{*}$ is the friction velocity, $T_{\mathrm{v}}$ is the average virtual temperature, $\kappa$ is the von-Karman constant, $g$ is the acceleration of gravity and $\overline{w^{\prime} T_{\mathrm{v} 0}^{\prime}}$ is the vertical turbulent flux of temperature, expressed by the product of instantaneous vertical velocity $w^{\prime}$ and instantaneous virtual temperature at the surface $T_{\mathrm{v} 0}^{\prime}$.

There exist different methods to determine the roughness parameters and the stability functions. Usually, $z_{0}$ is determined by the Charnock formula

$z_{0}=\frac{\alpha u_{*}^{2}}{g}$.

This relation reflects an increase of roughness lengths with increasing wind speed. The parameter $\alpha$ is in the different models chosen to be 0.0123 or 0.032 , partly depending on coastal or open-sea conditions of the grid-points.

In most models $C_{\mathrm{EN}}$ is either determined by a relation between $z_{\mathrm{q}}$ and $z_{0}$ (the simplest relation being $z_{\mathrm{q}}=z_{0}$ ) or by prescribing $C_{\mathrm{EN}}$. The different versions describe different wind speed influence on the neutral heat transfer coefficient. Experimental studies show that the neutral transfer coefficient $C_{\mathrm{EN}}$ depends only weakly, if at all, on wind speed (Large and Pond, 1982; DeCosmo et al., 1996). Thus a constant value of $C_{\mathrm{EN}}$ is introduced into some models.

The stability function $f_{\mathrm{E}}(z / L)$ is in most models related to the bulk Richardson number by analytical relations, e.g. according to Louis (1979) or Launiainen (1995). It should be noted that the stability function is mainly determined from experiments over land.

Precipitation can either be estimated with interpolation of direct measurements or calculated in the models. In the atmospheric models precipitation is calculated as stratiform (or grid-scale) precipitation and as convective (or subgrid-scale) precipitation. Stratiform precipitation occurs when a certain threshold value of relative humidity is exceeded in the grid box, according to Kessler (1969). Mass-flux convergence initiating cumulus convection is parameterised following the scheme of Tiedtke (1989). Entrainment, detrainment and evaporation of cloud water and/or precipitation are considered. The other two methods (SMHI/PROBEBaltic and the Interpolated Fields) are based on precipitation measurements. 
The specific parameterisations of the methods are described below. They differ only in some details. However, because of the interaction of all parameters in the models not only the parameterisation schemes of evaporation and precipitation influence the results.

\subsection{HIRLAM}

The HIRLAM forecast model is a three-dimensional limited area model covering the northern part of Europe. A detailed description of the model can be found in Källén (1996). In Rutgersson et al. (2001b) the turbulent fluxes are investigated. Here only some details of relevance for this study are given. In the present study, results from the operational HIRLAM version are used. HIRLAM is a numerical weather prediction model and data assimilation is included. The horizontal resolution reaches $22 \times 22 \mathrm{~km}^{2}$ with 31 vertical levels, with higher resolution closer to the surface. The lowest model level is situated at approximately $30 \mathrm{~m}$ above the surface. The vertical diffusion scheme is based on non-local first-order turbulent closure (Holtslag and Boville, 1993). A constant flux layer is assumed between the surface and the lowest model level. Parameters at lower height above the surface are calculated according to Monin-Obukhov similarity theory.

The turbulent fluxes over the sea in the surface layer of a grid box are determined from mean model parameters using a bulk formula, eq. (1). The transfer coefficients are calculated according to Louis (1979) and Louis et al. (1982). They are functions of the roughness length which is calculated with the Charnock formula, eq. (4), with a relatively high value of the Charnock constant, $\alpha=0.032$. Surface roughness and thus transfer coefficients are the same for latent heat and momentum, but different stability functions are used.

For sea surface temperature and ice cover, rather sparse measurements from the Baltic Sea are used in combination with satellite data giving SST maps which are updated every third day. For areas outside the Baltic Sea, analysed values are obtained from the European Centre for Medium Range Weather Forecasts (ECMWF). Each grid square in HIRLAM has a fraction of land, ice and sea, ranging from 0 to 1 . The reference version (HIRLAM) only analyses grid squares with $100 \%$ sea, whereas HIRLAM-coast also uses grid-squares including land to investigate the effect of coastal areas. For each hour the operational HIRLAM forecast with a forecast length of $6-11 \mathrm{~h}$ is used. For the vertical boundaries data are obtained from the global ECMWF model.

\section{2. $R E M O$}

REMO is a three-dimensional hydrostatic atmospheric regional model. It was set up at the Max-Planck-Institute for Meteorology (Hamburg, Germany) for simulation experiments within BALTEX. REMO is based on the operational Europamodell of Deutscher Wetterdienst (DWD) and can be used as a climate or forecast model. Alternatively, the physical parameterisations of DWD (Majewski, 1991; Heise, 1996) and of ECHAM-4 (Roeckner et al., 1996) are implemented and can be used. The model is described by Jacob and Podzun (1997) and by Hagedorn et al. (2000). For this study the version REMO4.3 with DWD physics is used. The model domain comprises Northern and Central Europe with the Baltic Sea in the centre. For simulations within PEP, REMO is set up in a $1 / 6^{\circ}$ grid, which corresponds approximately to $18 \mathrm{~km} \times 18 \mathrm{~km}$ in a rotated spherical grid (with the pole at $170^{\circ} \mathrm{W}, 32.5^{\circ} \mathrm{N}$ ). Swedish HIRLAM analyses with a lower horizontal resolution of $55 \mathrm{~km}$ are used as initial and boundary conditions, including the sea surface temperature (SST) of the Baltic Sea. REMO is run in the climate mode, i.e. only the boundary conditions are updated every $6 \mathrm{~h}$. No data assimilation is used. Simulated values of the surface layer fluxes are stored every hour as hourly means.

REMO has been used in several studies of the water and heat budget of the Baltic Sea (Jacob, 2001; Jacob et al., 2001; Ahrens et al., 1998) and proved to be a suitable tool for process studies as well as for longterm simulations.

For the present simulations, the physical parameterisations of DWD are implemented. The turbulent surface fluxes over the sea are parameterised by a bulk formulation with $z_{0}$ for momentum being determined by the Charnock formula using $\alpha=0.0123$. The roughness parameters for heat and water vapour are set equal to $z_{0}$ with an upper limit of $0.1 \mathrm{~m}$. The stability functions are related to the bulk Richardson number by an analytical expression according to Louis (1979).

The parameterisation of precipitation distinguishes between grid-scale stratiform precipitation and subgrid-scale convectice precipitation. Stratiform precipitation is determined by a prognostic procedure which explicitly regards cloud water and takes into account the interactions among cloud water, water vapour, 
rain and snow, namely condensation, evaporation, melting, freezing, autoconversion, accrescence, shedding and other processes. Convective precipitation is determined by a mass-flux convection scheme following Tiedtke (1989).

\subsection{PROBE-Baltic and the SMHI $(1 \times 1)^{\circ}$ database}

This method uses the ocean model PROBE-Baltic to get SST, ice concentration and calculate latent heat flux, PROBE-Baltic uses the SMHI $(1 \times 1)^{\circ}$ database (Rutgersson et al., 2001a) for the meteorological input (wind speed and direction, temperature, humidity, precipitation and cloudiness). The database covers the Baltic Sea drainage basin with a grid of $(1 \times 1)^{\circ}$ grid squares and uses all available synoptic weather stations in the area. These are interpolated in space using optimum interpolation. Only geostrophic wind is available in the SMHI data base and it is reduced to the $10-\mathrm{m}$ level by using a statistical relation. As the data base is strongly influenced by land the air temperature is corrected by considering the water temperature. The database can, however, also be assumed to be influenced by land surfaces for other parameters, since the majority of stations are over land and in coastal regions. The precipitation is assumed to be at least $10 \%$ too low (Rutgersson et al., 2001a). The underestimations depends on wind speed, temperature, the distance to the shoreline and the position of the gauges. It is difficult to introduce a general correction for the different errors. However, the probable underestimation of precipitation in the $\operatorname{SMHI}(1 \times 1)^{\circ}$ database should be kept in mind when comparing the results with other data.

The Baltic Sea model PROBE-Baltic (Omstedt and Nyberg, 1996) is an ocean process oriented model. The model divides the Baltic Sea into 13 sub-basins based upon data on bottom topography. Each subbasin is coupled to surrounding sub-basins via horizontal flows, in which simplified strait flow models are applied. River runoff is included via observed monthly means. The model calculates the horizontal mean properties of sea surface temperature, ice concentration and thickness in each sub-basin.

The model has been extensively verified showing good agreement between observed sea surface temperatures and ice as well as the vertical structure of temperature and salinity (Omstedt and Axell, 1998).

The turbulent fluxes are calculated from the bulk formula, eq. (1). The neutral transfer coefficient for momentum is described in WAMDI (1988). The neu- tral transfer coefficient for latent heat has a constant value, $C_{\mathrm{E}}=1.1 \times 10^{-3}$ (DeCosmo et al., 1996) and a stability dependence according to Launiainen (1995); see Rutgersson et al. (2001b) for details of the calculations. The combined method of determining precipitation over the Baltic Sea by the SMHI $(1 \times 1)^{\circ}$ database and evaporation by the ocean model PROBE-Baltic is in the following referred to as SMHI/PROBE-Baltic.

\subsection{Interpolated fields}

3.4.1. Evaporation. Evaporation over the Baltic Proper is calculated from interpolated fields of the respective parameters. Synoptic observations of voluntary observing ships and weather stations are provided by the Deutscher Wetterdienst (DWD). Ship observations are concentrated along the shipping routes; in general observation densities are highest in the southwestern parts of the Baltic Sea. Due to the sparsity of ship observations and their inhomogeneous distribution, leaving large gaps over the Baltic Sea, air pressure, geostrophic winds, temperatures, and humidities are analysed by using both ship and land observations.

Geostrophic winds and air pressure are analysed using an interpolation scheme based on the polynomial method (Panofsky, 1949), fitting a second-order pressure surface to both, wind and pressure observations. Air temperatures, dew points and water temperatures are interpolated by a simple linear averaging over areas of $2^{\circ}$ latitude times $2^{\circ}$ longitude. Due to the insufficient number of water temperature measurements, sea surface temperatures (SSTs) derived from satellite measurements are used as an additional source of information. The SSTs are kindly provided by the Bundesamt für Seeschiffahrt und Hydrographie (BSH). They are available every seventh day and represent averages of all available measurements during the preceeding 7-d period. Since this method is hampered by clouds, gaps exist also in the SST fields. Therefore interpolated water temperatures are calculated as centered averages over a period of $7 \mathrm{~d}$.

Ten-metre winds are obtained from geostrophic wind speeds by applying ageostrophic components for wind speed and direction. The ratios of $10-\mathrm{m}$ wind speeds to geostrophic wind speeds depend on the distance to the coast, taking into account whether the wind is blowing onshore or offshore. Details of the interpolation scheme are given in Bumke et al. (1998).

Heat fluxes are computed from interpolated fields according to eqs. (1) and (2) using bulk transfer coefficients of Isemer and Hasse (1987). These coefficients are tabulated for different wind speeds and 
air-sea temperature differences. The interpolated fields are available every $6 \mathrm{~h}$.

3.4.2. Precipitation: ship rain gauge data. Beginning in 1994 at least five voluntary ships have been equipped with ship rain gauges (SRGs Hasse et al., 1998) running between Lübeck and Helsinki through the Southern and Central Baltic Sea. The instruments are installed at sites on the ships where the flow is nearly horizontal. Measurements are typically stored as 8-min averages to allow nearly point measurements due to the high speeds of the ships (about $10 \mathrm{~m} / \mathrm{s}$ ). The measurements are randomly distributed in space and time. Their number exceeds 25000 in several months. The monthly averaged precipitation rates based on SRG measurements are calculated as the arithmetric mean of all data points located in the Baltic proper.

Precipitation fields over the Baltic Sea are derived from ship rain gauge measurements by using an interpolation scheme based on the Kriging method (Bacchi and Kottegoda, 1995; Rubel, 1996). This method has been improved by the introduction of a Monte-Carlo estimate of the sampling error taking into account the sparse data in some areas of the Baltic Sea. Also the effect that precipitation shows a mixed lognormal distribution is considered.

As an input of the interpolation scheme a first guess field is calculated by the use of weighted averages. Therefore seasonal spatial structure functions are derived from simultaneous 8 min SRG measurements on the merchant ships. According to the seasonal variation in atmospheric stability over the Baltic Sea, correlation lengths are shortest in autumn (Fig. 2).

Corresponding to the Kriging method the unknown true precipitation value $\hat{Z}$ at a given point $\mathbf{u}_{a}$ is given by a linear combination of weights $\lambda_{i}$ and random values of the considered processes $Z(\mathbf{u})$ located in the surrounding area at $\mathbf{u} \equiv(x, y)$ :

$\hat{Z}\left(\mathbf{u}_{a}\right)=\sum_{i=1}^{n} \lambda_{i}\left[Z\left(\mathbf{u}_{i}\right)+\delta\left(\mathbf{u}_{i}\right)\right]$.

The error $\delta\left(\mathbf{u}_{i}\right)$ is described by a "white-noise" random process. In this special case it is mainly determined by the sampling error due to the sparse data. To estimate the weights $\lambda_{i}$ it is a reasonable requirement that the mean squared deviation between the predictions and the truth reaches a minimum. Differentation leads to an equation system which also requires the knowledge of spatial covariances between

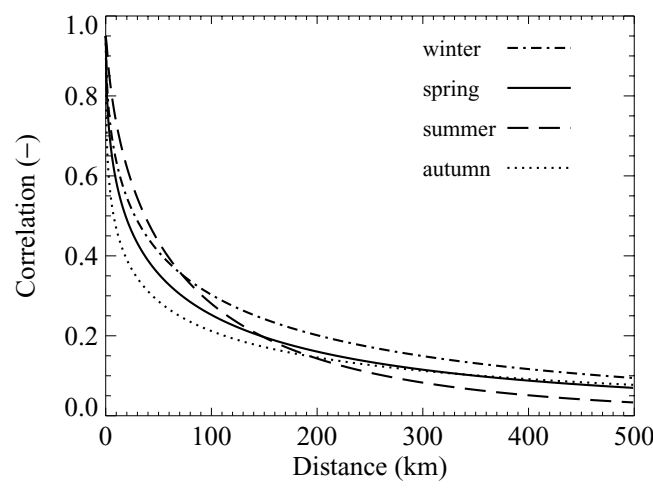

Fig. 2. Normalized spatial correlation functions for spring (March-May, solid line), summer (June-August, dashed line), autumn (September -November, dotted line) and winter (December-February, dashed-dotted line). Functions are based on the $8 \mathrm{~min}$ measurements for the period 1996-2000.

the data points. The autocovariances are estimated from the first-guess fields.

An example of a precipitation field derived from SRG measurements is given in Fig. 3. The corresponding error of this field is depicted in Fig. 4. In general, the error is less than $15 \%$, although in the Gulf of Finland it increases to more than $30 \%$.

\subsection{Comparison of the flux parameterisation schemes}

The different parameterisation schemes for latent heat fluxes over the ocean in HIRLAM, REMO,

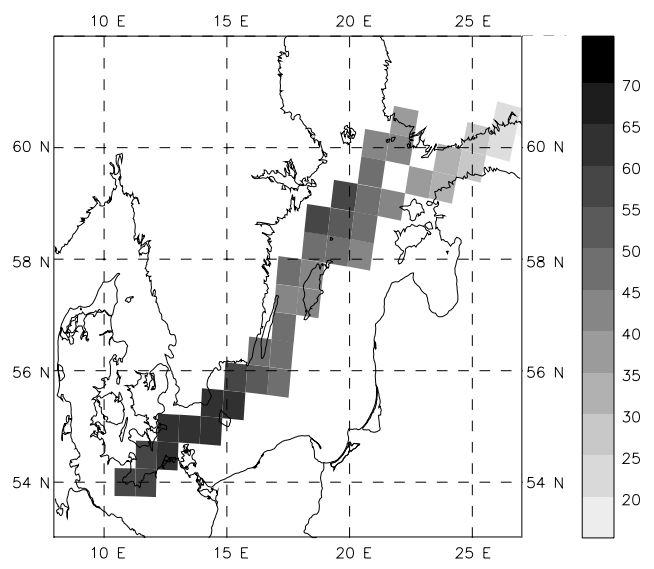

Fig. 3. Interpolated precipitation field in $\mathrm{mm} \mathrm{month}^{-1}$ for the period September 1998 to September 1999 using the Kriging method. 


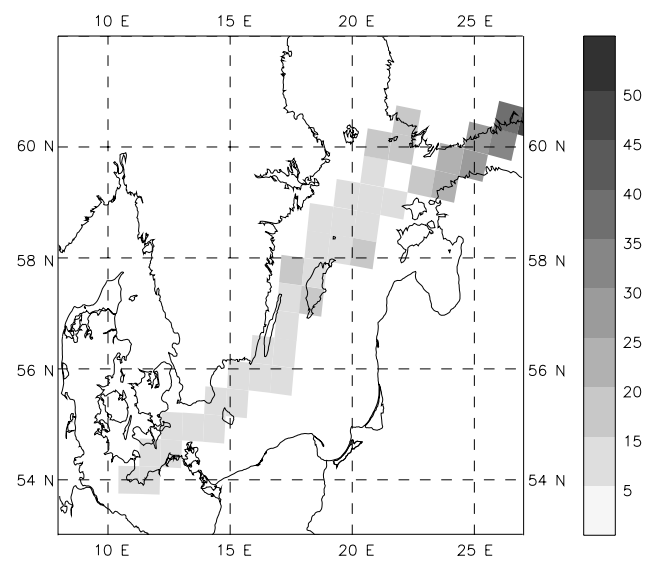

Fig. 4. Interpolation error in \% of the estimated precipitation field for the period September 1998 to September 1999.

SMHI/PROBE-Baltic and the Interpolated Fields are compared as "stand-alone versions" using test data (wind speed ranging from 2 to $30 \mathrm{~m} \mathrm{~s}^{-1}$, Richardson number ranging from -2 to 2 ). There are characteristic differences in the schemes: in the schemes of HIRLAM and REMO $z_{0}$ (and thus $C_{\mathrm{EN}}$ ) depends on $u_{*}$ via the Charnock formula, and the relation between $C_{\mathrm{EN}}$ and $u_{10}$ is not unique since it depends on stability. In the schemes of SMHI/PROBE-Baltic and the Interpolated Fields the neutral transfer coefficients depend on $u_{10}$ and the relation to $u_{*}$ is not unique but stability dependent. Figure 5 shows the $u_{10}$-dependence of the neutral heat transfer coefficient in the different mod-

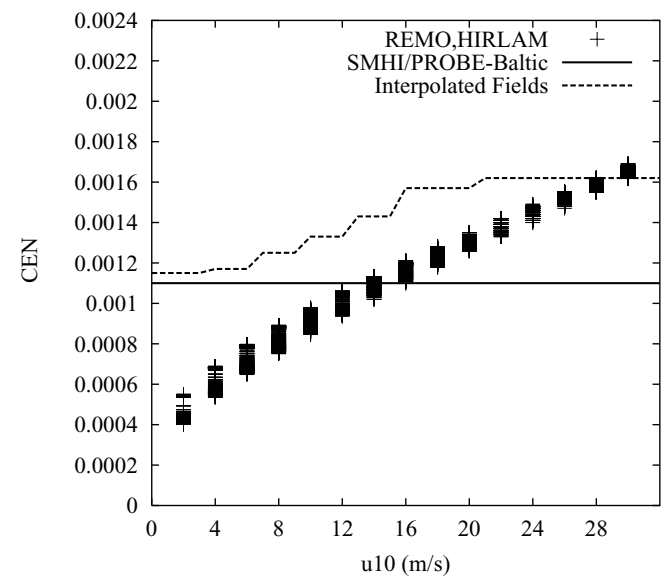

Fig. 5. Wind speed dependence of neutral transfer coefficient $C_{\mathrm{EN}}$ for different methods. els. While SMHI/PROBE-Baltic prescribes a constant transfer coefficient of $1.1 \times 10^{-3}$, there is an increase of $C_{\mathrm{EN}}$ with wind speed for the other schemes, which is stepwise for the scheme of Isemer and Hasse, 1987 used by the Interpolated Fields. An increasing heat transfer coefficient with increasing wind speed is also reported for models of NCEP/NCAR and ECMWF by Renfrew et al. (2002). Other schemes as the one of ECHAM4 (Roeckner et al., 1996) limit the increase with increasing wind speed by a threshold value (Hennemuth and Jacob, 2002).

Another difference in the parameterisation schemes lies in the use of stability functions, HIRLAM and REMO apply the formulae of Louis (1979) and SMHI/PROBE-Baltic the formulae of Launiainen (1995). In the Interpolated Fields the stability dependence of the transfer coefficients is included in a tabular formulation. Figure 6 shows the normalised transfer coefficients for the three schemes. The different formulations of $C_{\mathrm{EN}}$ depending either on $u_{*}$ or $u_{10}$ result in a different bulk Richardson number dependence. In particular, the wind-speed steps of the parameterisation due to Isemer and Hasse (1987) are obvious. During stable stratification REMO and HIRLAM use larger stability function values than SMHI/PROBE-Baltic and the Interpolated Fields. The opposite is true for unstable stratification where REMO and HIRLAM use smaller stability function values but with a strong wind speed dependence, via $z_{0}$. The different schemes lead to different heat fluxes (not shown here). The Isemer and Hasse parameterisation gives higher positive (i.e.

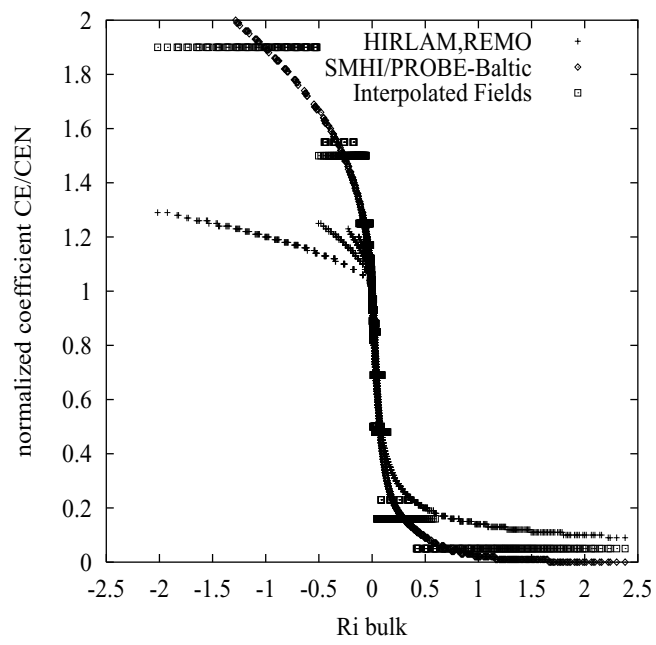

Fig. 6. Stability dependence of transfer coefficient $C_{\mathrm{EN}}$ for the different methods. 


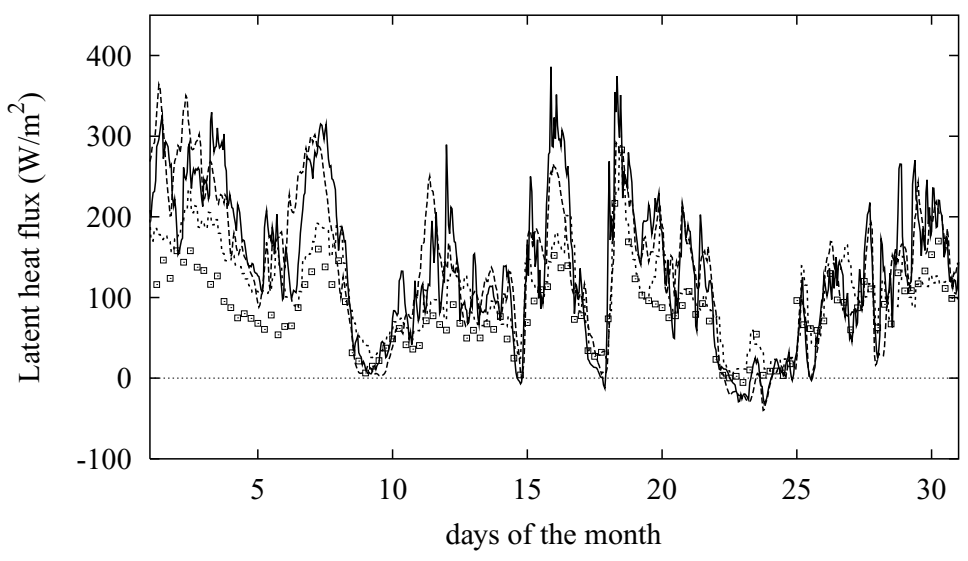

Fig. 7. Time series of latent heat flux at Christiansø for different models in October 1998. Solid line, HIRLAM; dashed line, REMO; dotted line, SMHI/PROBE-Baltic; squares, Interpolated Fields.

unstable) heat fluxes than the REMO and HIRLAM scheme, and SMHI/PROBE-Baltic gives lower negative (i.e. stable) heat fluxes than REMO and HIRLAM.

The parameterisation schemes for surface fluxes over the sea of all methods have been tested in previous studies. Rutgersson et al. (2001b) investigated the heat fluxes in HIRLAM and they found that reducing the strong wind speed dependence of the transfer coefficients leads to more realistic heat fluxes. In this study, however, the old version of HIRLAM is used with the tendency to overestimate evaporation during strong winds. Rutgersson et al. (2001b) also introduced the present parameterisation scheme with constant neutral transfer coefficient for latent heat into SMHI/PROBE-Baltic and found a better coincidence with observations than with the former scheme, which was similar to that of HIRLAM and REMO. REMO was also tested with different parameterisation schemes for fluxes over the sea (Hennemuth and Jacob, 2002), in particular with different wind speed dependences of the neutral transfer coefficient. However, in that study the effect of different transfer coefficients on the heat fluxes was found to be smaller than the effect of wrongly prescribed SST.

\section{Model accuracy}

\subsection{Intercomparison of the methods}

Intercomparison of the models and the data-based methods gives information about the expected accuracy of evaporation and precipitation. Evaporation results are compared for three months (September-
November 1998) which exhibit the largest latent heat fluxes over the Baltic Sea during mainly unstable stratification. For this period large relative errors in calculated fluxes would result in high absolute errors in the determination of net precipitation.

Figure 7 shows time series of latent heat fluxes for the grid point representing the site of Christians $\varnothing$ near Ronne (DK) for October 1998. The Interpolated Fields have a greater horizontal resolution than the atmospheric models and therefore for this comparison not the gridpoint adjacent to the island but the next one is chosen. The general structure of periods with small and large fluxes is reproduced by all models. The two atmospheric models HIRLAM and REMO are rather close together while the oceanographic model and the Interpolated Fields give smaller fluxes, predominantly during periods with very high fluxes. The reason may partly be the rather coarse horizontal resolution (for SMHI/PROBE-Baltic) and the sparsity of observations (for the Interpolated Fields). This leads to smoothing. The differences which could be expected from the parameterisation schemes are superimposed by differences in the mean parameters.

Table 1 gives an overview over the comparison of latent heat fluxes for the three autumn months and the site Kopparnäs near Helsinki (FIN), where direct measurements of latent heat flux are available over a couple of weeks. The last four rows show the comparison with measured data (see Section 4.2).

The correlation coefficients vary between 0.56 and 0.81 , the biases between -9 and $22 \mathrm{~W} \mathrm{~m}^{-2}$. The models HIRLAM and REMO correlate well, which is not surprising since REMO uses HIRLAM analyses 
Table 1. Correlation coefficients (C) between modelled and measured latent heat fluxes and their biases (bias) and rms errors (rms) for the station Kopparnäs in autumn 1998 (09/98-11/98) (bias and rms error in $\mathrm{W} \mathrm{m}^{-2}$ )

\begin{tabular}{lccr}
\hline Compared data & $C$ & Bias & Rms \\
\hline HIRLAM vs REMO & 0.813 & 21.7 & 44.2 \\
HIRLAM vs. SMHI/PROBE-Baltic & 0.700 & 14.2 & 48.8 \\
HIRLAM vs. Interpolated Fields & 0.688 & 13.4 & 52.0 \\
REMO vs SMHI/PROBE-Baltic & 0.723 & 7.30 & 30.6 \\
REMO vs. Interpolated Fields & 0.644 & -8.54 & 36.9 \\
SMHI/PROBE-B. vs. Interpolated Fields & 0.558 & -2.70 & 36.2 \\
Measurements vs HIRLAM & 0.740 & 25.0 & 46.8 \\
Measurements vs. REMO & 0.712 & 4.29 & 29.5 \\
Measurements vs. SMHI/PROBE-Baltic & 0.611 & -11.5 & 34.5 \\
Measurements vs Interpolated Fields & 0.784 & 12.5 & 30.0 \\
\hline
\end{tabular}

for the boundary forcing, but bias and rms error are rather large. The agreement of HIRLAM and REMO with SMHI/PROBE-Baltic is better than with the Interpolated Fields, although the Interpolated Fields are biased only by 9 to $-13 \mathrm{~W} \mathrm{~m}^{-2}$ to the other models.

Frequency distributions of 6-h mean values of latent heat fluxes for a site in the central Baltic Sea (Fig. 8) reveal differences between the four methods. The two numerical models HIRLAM and REMO show broad distributions with high frequency of fluxes larger than $150 \mathrm{~W} \mathrm{~m}^{-2}$, whereas the other two methods compute fluxes which mainly range from 0 to $150 \mathrm{~W} \mathrm{~m}^{-2}$. There are two kinds of reasons for this. One is the tendency of the atmospheric models to overestimate surface fluxes due to the parameterisation scheme, in particular during strong wind situations and due to the delay in actualisation of SST, which leads to high fluxes in situations of decreasing SST as occurring in autumn (see Section 3.3). The other reason is the lack of extreme fluxes in methods which make use of interpolated meteorological parameters as SMHI/PROBE-Baltic and the Interpolated Fields do.

The frequency distributions of differences of fluxes calculated by the different methods are rather broad and show values of $\pm 80 \mathrm{~W} \mathrm{~m}^{-2}$ and more (not shown here). This appears to be large, in particular for the two atmospheric models, but it can to a large degree be explained by time shifts between the methods which is obvious from Fig. 7. HIRLAM and REMO are operated in different modi (forecast modus and climate modus) and therefore do not run synchronous which results in a broad distribution of flux differences.

A detailed comparison of precipitation calculated by the different methods is difficult because the results have different time and space resolution. In a former study (Rutgersson et al., 2001a) a comparison of SMHI $(1 \times 1)^{\circ}$ database and SRG precipitation leads to the conclusion that comparisons on a time scale shorter than one month are not reliable.

Here, precipitation from REMO and the Interpolated Fields is compared. For this purpose, REMO fields (horizontal resolution of $1 / 6^{\circ}$ ) are averaged onto a $0.5^{\circ} \times 0.5^{\circ}$ grid to reach the spatial resolution of the SRG precipitation field. The differences between REMO and the SRG field are given in Fig. 9. In the southern Baltic the deviations are in general rather small $\left( \pm 5 \mathrm{~mm}\right.$ month $\left.^{-1}\right)$. Larger differences occur especially in the north-east near the Finnish coast (>20 $\left.\mathrm{mm} \mathrm{month}^{-1}\right)$.

The discrepancies in this area may be explained by the large error in the estimated SRG field (cf. Fig. 4), but also by the uncertainties in the REMO predictions. We have to keep in mind that REMO gridboxes may contain land and sea, while the results of the SRGs are representative only for the sea.

\subsection{Comparison with observational data}

PEP in BALTEX was designed to give enhanced observations for the improvement of model parameterisation of turbulent fluxes in the surface layer over the sea (Smedman et al., 1998). So in this section, PEP measurements are here compared to model fluxes. The measuring sites are located on a transsect of the Baltic Sea from southwest to northeast, either on small islands or near to the coast (Fig. 1). Each site has a wide sector open to wind from the undisturbed sea, thus representing for this sector a marine station. Only data from this sector are used for comparison with model results at gridpoints closest to the site. The selection of 

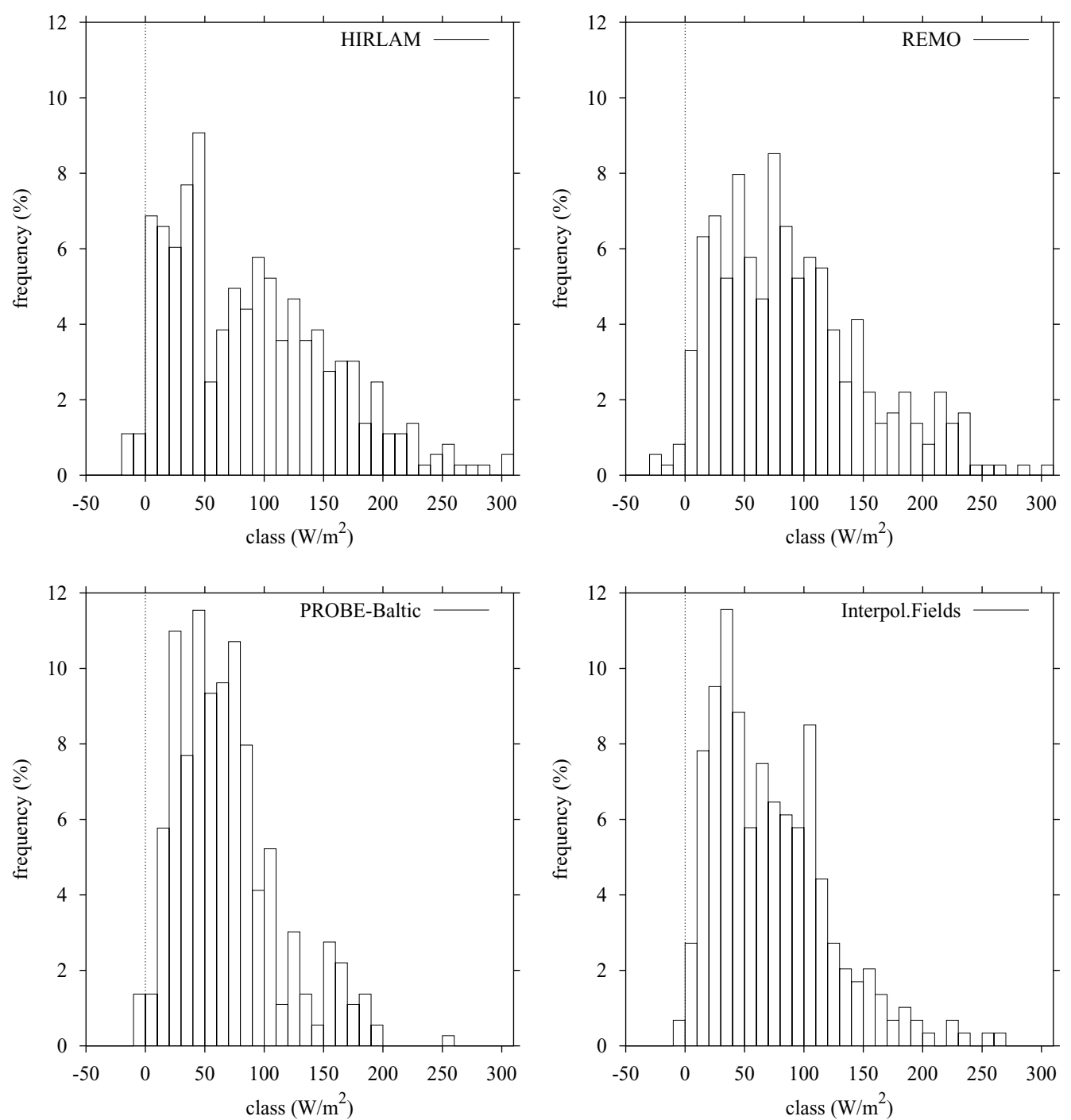

Fig. 8. Frequency distributions of hourly values of latent heat fluxes computed by the four methods for the site of Östergarnsholm in the central Baltic Sea for the three autumn months.

onshore wind situations and gaps in the measurements provide data only for $26-45 \%$ of the one-year period (Hennemuth and Jacob, 2002), hence the data set is reduced.

Specific model fluxes have already been compared with these measurements, e.g. Rutgersson et al. (2001b) showed that the evaporation in both SMHI/PROBE-Baltic and HIRLAM was overestimated. This could to a large extent be explained by errors in air-water temperature and humidity differ- ences. Hennemuth and Jacob (2002) tested REMO results against PEP measurements. They found that SST in special situations like cold air outbreak may change rapidly; an update twice a week for the model forcing is not suitable to simulate right surface fluxes.

Here we compare in Fig. 10 the simulated fluxes from two models (REMO and SMHI/PROBE-Baltic) with the measured fluxes at Christians $\emptyset$. During the first part of the month, modelled and measured fluxes are of the same order and appear to show the same

Tellus 55A (2003), 4 


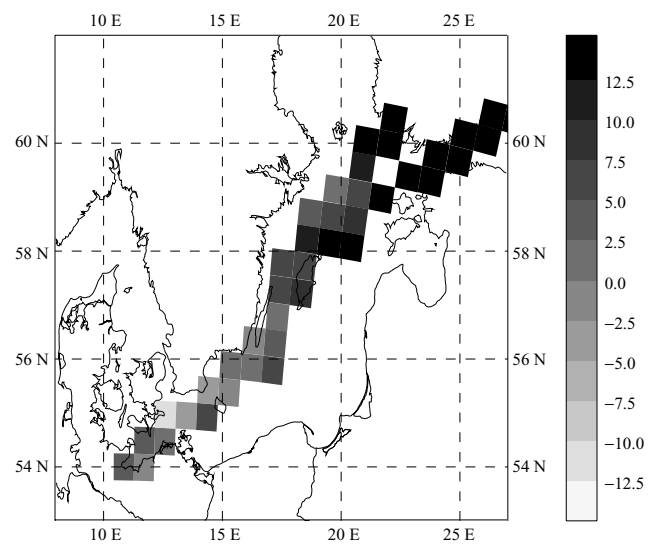

Fig. 9. Differences in mm month ${ }^{-1}$ between REMO precipitation predictions and SRG fields for the period September 1998 to September 1999.

major tendencies. However, from 23 to 27 November these are even of opposite sign, probably indicating wrong model SST. For the entire period of three months the correlation coefficient, bias and rms error of model results and measurements for Kopparnäs are given in the last four rows in Table 1. The differences between the methods and observations are comparable to the differences between the different methods.

There are several reasons for deviations of model fluxes from measured fluxes. (1) The horizontal resolution of the models of $20-50 \mathrm{~km}$ smoothes data compared to point measurements, particularly in coastal regions. (2) In HIRLAM and REMO SST is prescribed. The SST fields are derived from measurements (satel- lite, buoys, ... etc.) and in general only updated twice a week. This lack of sufficient resolution in space and time causes deviations from the actual SST, particularly near coasts. (3) Simulated parameters like temperature, humidity and wind speed in the surface layer over the sea may deviate from actual values (Rutgersson et al., 2001b). (4) The parameterisation schemes for surface fluxes over the sea in the models are not adequate for all atmospheric and oceanographic conditions. The proper representation of surface waves in the Baltic Sea (via the factor $\alpha$ in the Charnock formula), the realistic parameterisation of stable atmospheric stratification and of swell, is not yet implemented in these models (Rutgersson et al., 2001c).

Observations in the open ocean on board of ships are too sporadic to give reasonable results (Bumke and Clemens, 2001).

Point measurements of precipitation are less suitable for comparison with model results than in the case of surface heat fluxes, since precipitation is strongly varying in time and space. To come to reasonable results a large number of points should be used.

Estimated precipitation rates of the Interpolated Fields and REMO are compared to measurements at synoptic stations (Synop-SRG and Synop-REMO). Synoptic measurements were made available by the DWD and corrected by Rubel for the wind error, wetting loss and loss by evaporation (Rubel and Hantel, 1999). All synoptic stations are chosen for comparison, which are within a distance of less than $25 \mathrm{~km}$ to the centre of grid cells of the precipitation fields. Grid boxes where the Kriging fields have

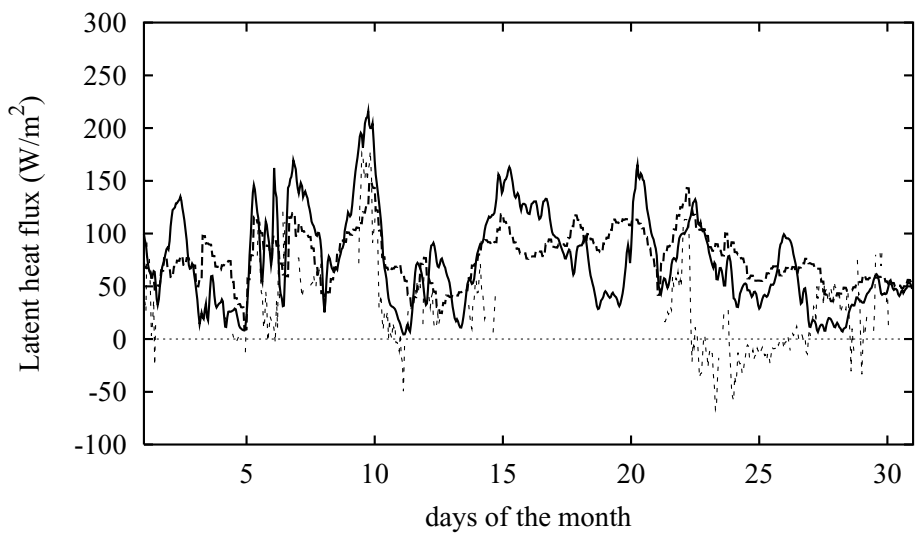

Fig. 10. Latent heat flux in $\mathrm{W} \mathrm{m}^{-2}$ at Christians $\varnothing$ calculated by two models REMO (solid line) and SMHI/PROBE-Baltic (dashed line) for November 1998, compared to the measured flux (dotted line). 


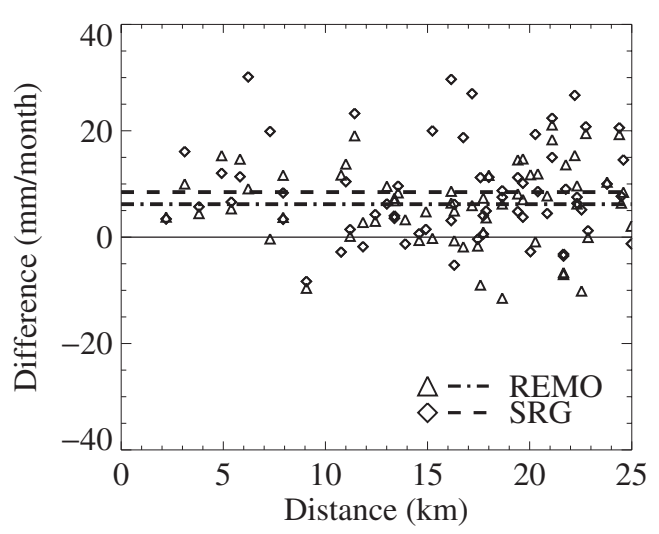

Fig. 11. Comparison between mean monthly precipitation measured at synoptic stations and analysed fields, the latter estimated from the ship rain gauges, and precipitation calculated by REMO. Synoptic observations are corrected for wind error, evaporation and wetting loss using the method of Rubel (1996). Only stations with a distance less than $25 \mathrm{~km}$ from the centre of a gridbox have been used.

relative errors of more than $25 \%$ are excluded. The result is shown in Fig. 11.

Generally the bias between synoptic observations and SRG or REMO is small. Fields derived from SRG measurements by Kriging give slightly higher precipitation (by $8.5 \mathrm{~mm} \mathrm{month}^{-1}$ ) than synoptic observations compared to REMO (6.2 mm month $\left.{ }^{-1}\right)$. The standard deviations to synoptic observations are

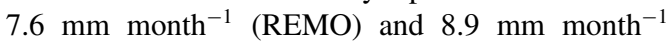
(SRG), which agrees well with the estimated error of the SRG estimates (Fig. 4).

Areal data sets of precipitation would be more suitable for comparison with the model results, but there are specific problems in such data sets. The BALTRAD network (Michelson et al., 2000), which generates data sets of accumulated precipitation over the Baltic Sea, started operational work only in late 1999, too late for the purpose of PEP. Other sources for areal totals of precipitation from observations are e.g. MESAN (Häggmark et al., 2000) and GPCC (GPCC, 2001), but these data sources are mainly based on observations over land.

\section{Net precipitation of the Baltic Sea and subbasins}

Precipitation, evaporation and net precipitation from September 1998 to August 1999 are analysed using the methods described in the previous sections.

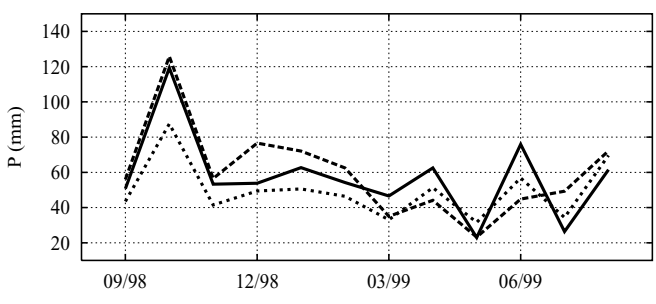

(a)

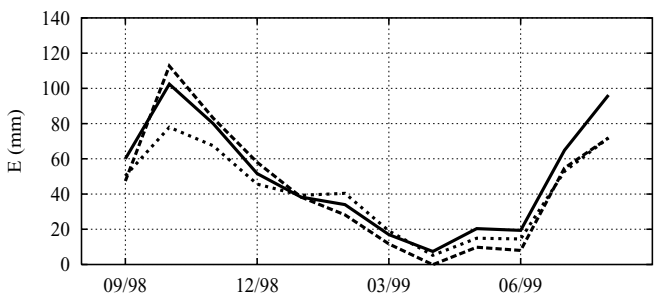

(b)

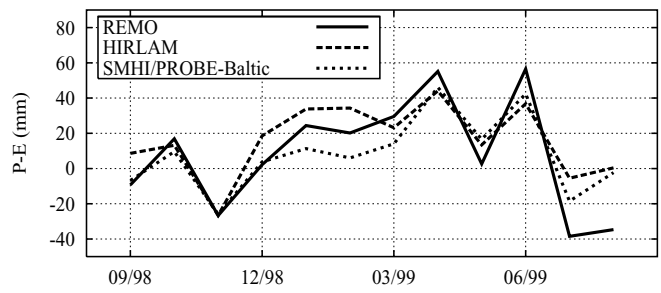

(c)

Fig. 12. Monthly averages of P (a), E (b) and P-E (c) for the entire Baltic Sea using different methods for the period September 1998 to August 1999.

In Figs. 12 and 13 as well as Tables 2 and 3 the monthly and annual averages of such estimates are presented.

In Fig. 12 the results for the entire Baltic Sea are shown. The results of the Interpolated Fields are missing, because they only cover the Baltic Proper. The effect of including the coastal points in HIRLAM is also shown in Table 2. It is found to have the greatest effect for evaporation. In September-February the coastal values are $2-10 \mathrm{~mm}$ lower as monthly averages, but for April-June they are 1-4 mm higher. For precipitation the values are $0.5-4 \mathrm{~mm}$ lower when including the coastal points in September-December and 0.5$3 \mathrm{~mm}$ higher in March-June. The annual net effect in $P-E$ is $18 \mathrm{~mm}$ higher $P-E$ (or $10 \%$ ) when 


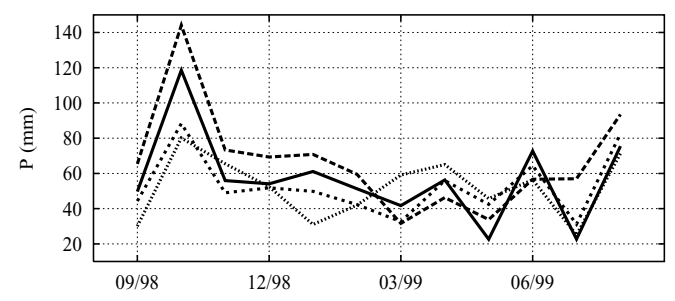

(a)

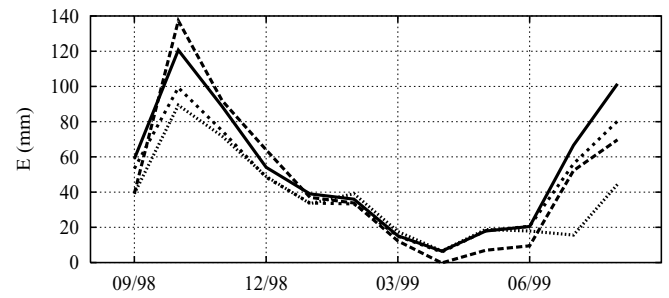

(b)

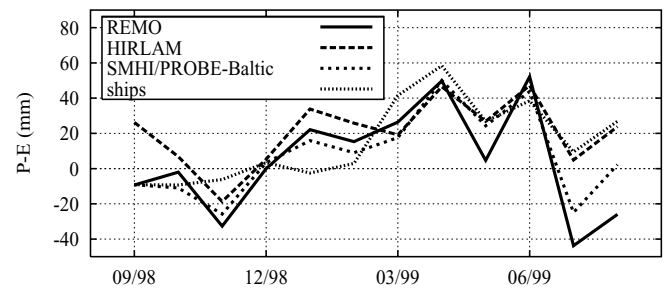

(c)

Fig. 13. Same as Fig. 12, but for the Baltic proper.

Table 2. Annual means of precipitation (P), evaporation $(\mathrm{E})$ and net precipitation $(\mathrm{P}-\mathrm{E})$ for the entire Baltic Sea using different methods. The investigated period is September 1998 to August 1999, except for SMHI/PROBE-Baltic with 18 yr from 1981 to 1998 (Rutgersson et al., 2002)

\begin{tabular}{lccc}
\hline Model & $P(\mathrm{~mm})$ & $E(\mathrm{~mm})$ & $P-E(\mathrm{~mm})$ \\
\hline REMO & 690 & 592 & 98 \\
HIRLAM & 718 & 524 & 194 \\
HIRLAM coast & 711 & 501 & 209 \\
SMHI/PROBE-Baltic & 596 & 499 & 96 \\
SMHI/PROBE-Baltic & 596 & 467 & 129 \\
$\quad$ 18 yr & & & \\
\hline
\end{tabular}

Table 3. As Table 2, but for the Baltic proper

\begin{tabular}{lccc}
\hline Model & $P(\mathrm{~mm})$ & $E(\mathrm{~mm})$ & $P-E(\mathrm{~mm})$ \\
\hline REMO & 682 & 625 & 57 \\
HIRLAM & 801 & 554 & 247 \\
HIRLAM coast & 794 & 532 & 262 \\
SMHI/PROBE-Baltic & 634 & 539 & 95 \\
Interpolated Fields & 624 & 442 & 181 \\
SMHI/PROBE-Baltic & 585 & 552 & 32 \\
$\quad$ & & & \\
\hline
\end{tabular}

including the coastal points. In the figures only HIRLAM results with coastal points are shown.

The annual means for the different models are shown in Table 2. One significant difference between the models is that both HIRLAM and REMO give larger precipitation than SMHI/PROBE-Baltic, in REMO precipitation is larger throughout the year and in HIRLAM mainly during autumn and winter. However, it should be kept in mind that the SMHI database underestimates precipitataion (see Section 3.3). Obviously, the evaporation is larger in REMO and HIRLAM during autumn than in SMHI/PROBEBaltic (Fig. 7). For HIRLAM this is consistent with what has been found earlier, with too high evaporation at high wind speeds (Rutgersson et al., 2001b). However, during spring the evaporation in HIRLAM is lower than in the other models.

The net effect is a higher $P-E$ in HIRLAM and REMO than in SMHI/PROBE-Baltic, mainly during late winter. For the annual average, SMHI/PROBEBaltic and REMO show similar values of $P-E$, since both $P$ and $E$ are larger than in the SMHI/PROBEBaltic. Net precipitation in HIRLAM is higher than in the other models.

When relating the investigated year to SMHI/ PROBE-Baltic results for $18 \mathrm{yr}$ in Table 2, this year appears to be representative for a longer period, as the precipitation is close to the long-term average, evaporation slightly higher resulting in a lower $P-E$. The results of all methods lie within the uncertainty range for $P-E$ estimated by Rutgersson et al. (2002), although the precipitation and evaporation values of HIRLAM and REMO appear to be large.

The Baltic Sea is often divided into several subbasins. When analysing precipitation and evaporation rates from the Baltic Proper (Fig. 13) some new features can be observed. For this part of the Baltic Sea also the results of the Interpolated Fields are included. For the annual mean (Table 3) HIRLAM gives 
for this basin even higher precipitation and evaporation than SMHI/PROBE-Baltic. This is evident during autumn and winter (Fig. 13), while during spring and early summer the evaporation is lower than that of SMHI/PROBE-Baltic. In REMO precipitation and evaporation are higher than SMHI/PROBE-Baltic during summer and autumn and similar during the rest of the year. The results of the Interpolated Fields and SMHI/PROBE-Baltic agree well, except during spring. The SMHI $(1 \times 1)^{\circ}$ database is dominated by land and coastal stations and can thus not include all ocean features, but on the other hand there could be a problem of low data coverage in single months when using ship data. The evaporation for SMHI/PROBEBaltic and the Interpolated Fields agrees well except for the two last months, but both are lower than the atmospheric models. Consequently, net precipitation varies among the models and the Interpolated Fields with up to $50 \mathrm{~mm}$ for a single month, reaching nearly $200 \mathrm{~mm}$ for the annual sum, the annual values of the Interpolated Fields and HIRLAM being large ones.

When comparing to the long-time average, the selected period is slightly different for the Baltic Proper. The net $P-E$ is higher during most of the year, mainly due to higher precipitation. It can thus be concluded that the investigated year tends to be wetter in the south and drier in the north than the 18-yr average. The evaporation is fairly close to normal. For the Baltic Proper it is lower than normal by $13 \mathrm{~mm}$, indicating a slightly colder period, at least in the months with high evaporation, i.e. the autumn months. For the entire Baltic Sea the evaporation is higher than normal, indicating that the northern and eastern basins of the Baltic Sea are warmer on average, in agreement with the temperature and precipitation analysis in Section 2.

\section{Conclusions}

Within PEP in BALTEX we have attempted to determine the net precipitation over the Baltic Sea with different methods for the period from September 1998 to August 1999. Using two atmospheric regional models with prescribed SST values, one Baltic Sea ocean model forced with observed gridded meteorological data and one method which makes use of interpolated observations, we conclude after model intercomparison and comparison to measurements and classification of the specific year: (1) The investigated period (September 1998 to August 1999) is slightly warmer and wetter than the climatological normal. (2) All methods indicate that the net precipitation during the studied one-year period is positive. However, the estimates differ strongly from 96 to $209 \mathrm{~mm}$ for the entire Baltic Sea and from 57 to $262 \mathrm{~mm}$ for the Baltic proper. An estimation of the net precipitation of the Baltic Sea during the studied one year period is $150 \pm 50 \mathrm{~mm}$ or approximately $1500 \pm 500 \mathrm{~m}^{3} \mathrm{~s}^{-1}$. This value lies within the range for a $100 \mathrm{yr}$ period, found by Rutgersson et al. (2002). (3) The two 3D regional scale atmospheric models overestimate precipitation as well as evaporation during autumn and winter as compared to the data-based methods. (4) The horizontally averaged basin model SMHI/PROBE-Baltic and the Interpolated Fields based on rather sparse ship measurements appear to smooth large evaporation events. (5) $P-E$ is higher in HIRLAM and in the Interpolated Fields than in REMO and SMHI/PROBE-Baltic, although REMO gives both larger evaporation and larger precipitation values than SMHI/PROBE-Baltic. (6) The results of the four methods have been compared to measurements of evaporation and precipitation over the Baltic Sea, the deviations are comparable to those between the methods. (7) The large uncertainty in the determination of evaporation and precipitation over the Baltic Sea is due to specific shortcomings in the respective models. Recommendations for the atmospheric models are: (i) coupling to the ocean; (ii) use of a neutral transfer coefficient for heat with reduced wind speed dependence as compared to momentum transfer; (iii) adaption of parameterisation schemes for turbulent fluxes for the full range of atmospheric conditions. This item needs further investigation. Recommendations for the measurement-based methods can only be the demand for more observations over the Baltic Sea, from ships, buoys and remote sensors such as Radar. (8) At present, reliable results for the net precipitation over the Baltic Sea with higher accuracy are hardly available.

\section{Acknowledgements}

This work was to a large part funded by the $\mathrm{Eu}-$ ropean Union within project no. ENV4-CT97-0484. The SYNOP data of 13 stations around the Baltic Sea were provided by Dr. E. Reimer, Institut für Meteorologie, Freie Universität Berlin, Germany. We thank Angela Lehmann and her team from the Deutscher Wetterdienst for making the synoptic observations available for us, Franz Rubel from the University of Vienna for correcting the land-based precipitation measurements, and the Poseidon Shipping Company and 
its crews, who gave us the opportunity to perform ship rain gauge measurements over the Baltic Sea on their ships. Sven-Erik Gryning, Risø National Laboratoy, Roskilde, Denmark is gratefully acknowledged for the observational data of Christians $\varnothing$ and Bengt
Tammelin, Finnish Meteorological Institute, Helsinki, Finland for the Kopparnäs data.

We also thank Hartmut Graßl (MPI for Meteorology, Hamburg, Germany) and two anonymous reviewers for helpful comments and suggestions.

\section{REFERENCES}

Ahrens, B., Karstens, U., Rockel, B. and Stuhlmann, R. 1998. On the validation of the atmospheric model REMO with ISCPP data and precipitation measurements using simple statistics. Meteorol. Atmos. Phys. 68, 127-142.

Bacchi, B. and Kottegoda, N. 1995. Identification and calibration of spatial correlation patterns of rainfall. J. Hydrol. 165, 311-348.

BALTEX 1995. Baltic Sea Experiment BALTEX. Initial Implementation Plan. In Technical report, International BALTEX Secretariat. GKSS Research Center, Geesthacht, Germany, $84 \mathrm{pp}$.

Bumke, K. and Clemens, M. 2001. PEP report., PEP in BALTEX, Final Report (ed. A. Smedman). Brussels, Belgium.

Bumke, K., Karger, U., Hasse, L. and Niekamp, K. 1998. Evaporation over the Baltic Sea as an example of a semiclosed sea. Contrib. Atmos. Phys. 71, 249-26.

DeCosmo, J., Katsaros, K. B., Smith, S. D., Anderson, R. J., Oost, W. A., Bumke, K. and Chadwick, H. 1996. Air-sea exchange of water vapor and sensible heat: The HEXOS results. J. Geophys. Res. 101, 12 001-12016.

GPCC. 2001. Global Precipitation Climatology Centre homepage: http://www.-dwd.de/research/gpcc.

Hagedorn, R., Lehmann, A. and Jacob, D. 2000. A coupled high resolution atmosphere-ocean model for the BALTEX region. Meteorol. Z. 9, 7-20.

Häggmark, L., Ivarsson, K.-I., Gollvik, S. and Olofsson, P.-O. 2000. MESAN, an operational mesoscale analysis system. Tellus 52A, 2-20.

Hasse, L., Grossklaus, M., Uhlig, K. and Timm, P. 1998. A ship rain gauge for use in high wind speeds. Atmos. Oceanic Technol. 15, 380-386.

Heise, E. 1996. An investigation of water and energy budgets for the BALTEX region based on short-range numerical weather predictions. Tellus 48A, 693-707.

Hennemuth, B. and Jacob, D. 2002. One year measurement and simulation of turbulent surface heat fluxes over the Baltic Sea. Meteorol. Z. 11, 105-118.

Holtslag, A. A. and Boville, B. A. 1993. Local versus nonlocal boundary-layer diffusion in a global climate model. J. Climate 10, 1825-1842.

Isemer, H. J. and Hasse, L. 1987. The Bunker Climate Atlas of the North Atlantic: 2. Air sea interactions. Springer, Berlin.

Jacob, D. 2001. A note to the simulation of the annual and inter-annual variability of the water budget over the Baltic Sea drainage basin. Meteorol. Atmos. Phys. 77, 61-73.

Jacob, D. and Podzun, R. 1997. Sensitivity studies with the regional climate model REMO. Meteorol. Atmos. Phys. 63, 119-129.
Jacob, D., den Hurk, B. V., Andræ, U., Elgered, G., Fortelius, C., Graham, L., Jackson, S., Karstens, U., Köpken, C., Lindau, R., Podzun, R., Rockel, B., Rubel, F., Sass, B., Smith, R. and Yang, X. 2001. A comprehensive model inter-comparison study investigating the water budget during the BALTEX-PIDCAP period. Meteorol. Atmos. Phys. 77, 19-43.

Källén, E. 1996. Hirlam Documentation Manual, System 2.5. Technical report, SMHI, SE-601 76 Norrköping, Sweden.

Kessler, E. 1969. On the distribution and and continuity of water substance in atmospheric circulation volume 10. Meteorological Monographs, Am. Meteorol. Soc., Boston, MA.

Large, W. and Pond, S. 1982. Sensible and latent heat flux measurements over the ocean. J. Phys. Oceanogr. 12, 464482.

Launiainen, J. 1995. Derivation of the relationship between the Obukhov stability parameter and the bulk Richardson number for flux profiles. Boundary-Layer Meteorol. 76, $165-179$.

Louis, J. F. 1979. A parametric model of vertical eddy fluxes in the atmosphere. Boundary-Layer Meteorol. 17, 187202.

Louis, J. F., Tiedtke, M. and Geleyn, J. F. 1982. A short history of the PBL parameterization at ECMWF. Proc. ECMWF Workshop on boundary-layer parameterization, Shinfield Park, Reading, U.K., 59-79.

Majewski, D. 1991. The Europa-Modell of the Deutscher Wetterdienst. Seminar Proc. ECMWF 2, Shinfield Park, Reading, U.K., 147-191.

Michelson, D., Andersson, T., Koistinen, J., Collier, C., Riedl, J., Szurc, J., Gjertsen, U., Nielsen, A. and Overgaard, S. 2000. BALTEX Radar Data Centre - Products and their methodologies. SMHI Reports 90, Meteorology and Climatology, Norrköping, Sweden.

Omstedt, A. and Nyberg, L. 1996. Response of Baltic Sea ice to seasonal, interannual forcing and climate change. Tellus 48A, 644-662.

Omstedt, A. and Axell, L. 1998. Modeling the seasonal, interannual, and long-term variations of salinity and temperature in the baltic proper. Tellus 50A, 637-652.

Omstedt, A., Meuller, L. and Nyberg, L. 1997. Interannual, seasonal and regional variations of precipitation and evaporation over the Baltic Sea. Ambio 26, 484-492.

Panofsky, H. 1949. Objective weather map analysis. J. Meteorol. 6, 386-392.

Raschke, E. and 35 co-authors. 2001. BALTEX (Baltic Sea Experiment): A European contribution to investigate the 
energy and water cycle over a large drainage basin. Bull. Am. Meteorol. Soc. 82, 2389-2413.

Renfrew, I., Moore, G., Guest, P. and Bumke, K. 2002. A comparison of surface-layer, surface heat flux and surface momentum flux observations over the labrador sea with ECMWF analyses and NCEP reanalyses. Phys. Oceanogr. 32, 383-400

Roeckner, E., Arpe, K., Bengtsson, L., Christoph, M., Claussen, M., Dümenil, L., M. Esch, Giorgetta, M., Schlese, U. and Schulzweida, U. 1996. The atmospheric general circulation model ECHAM-4: Model description and simulation of present day climate, Report 218, MaxPlanck-Inst.f.Meteorologie, Hamburg, Germany.

Rubel, F. 1996. PIDCAP quick look precipitation atlas. Österreichische Beiträge zu Meteorologie und Geophysik 15, Institute for Meteorology and Geophysics, University of Vienna, Austria.

Rubel, F. and Hantel, M. 1999. Corrections of daily rain gauge measurements in the Baltic Sea drainage basin. Nordic Hydrol. 30, 191-208.

Rutgersson, A., Bumke, K., Clemens, M., Foltescu, V., Lindau, R., Michelson, D. and Omstedt, A. 2001a. Precipita- tion estimates over the Baltic Sea: present state of the art. Nordic Hydrol. 32, 285-314.

Rutgersson, A., Smedman, A.-S. and Omstedt, A. 2001b. Measured and simulated latent and sensible heat fluxes at two marine sites in the Baltic Sea. Boundary-Layer Meteorol. 99, 53-84.

Rutgersson, A., Smedman, A.-S. and Högström, U. 2001c. The use of conventional stability parameters during swell. J. Geophys. Res. 106, 27 117-27 134.

Rutgersson, A., Omstedt, A. and Räisänen, J. 2002. Net precipitation over the Baltic Sea during present and future climate conditions. Climate Res. 22, 27-39.

Smedman, A., Gryning, S.-E., Bösenberg, J., Tammelin, B., Andersson, T., Omstedt, A. and Bumke, K. 1998. PEP in BALTEX. a pilot study of evaporation and precipitation in the Baltic Sea. Proc. Second Study Conf. on BALTEX, Rügen, Germany, 206-207.

Tiedtke, M. 1989. A comprehensive mass flux scheme for cumulus parameterization in large-scale models. Mon. Wea. Rev. 117, 1779-1800.

WAMDI. 1988. The WAM model: A third generation ocean wave prediction model. J. Phys. Oceanogr. 18, 1775-1810. 